\section{Fellowship fund would help eastern Europe to retain its young talent}

Sir-Eastern European countries have a tradition of stressing the importance of solid scientific education and research. Even under communism, Polish scientists allowed to work in western laboratories were able to perform at the level of their colleagues from the host country.

This level of performance has been improving since the rise of democracy. Recently, leading western European laboratories - the European Molecular Biology Laboratory (EMBL) and the Max Planck Society - have created special PhD programmes to attract talented young scientists from eastern Europe. These programmes provide excellent opportunities for students to begin their scientific careers in well-funded western European laboratories. Unfortunately, they also have drawbacks. One is the risk of a flight of $\mathrm{PhD}$ candidates from eastern European laboratories such as those in Poland.

In Poland, there have been two major changes in the way laboratories are funded and operated since the transition to a democratic system of government. As a result, a new emphasis has been placed on the importance of graduate students in making a research programme successful. First, there has been the creation of a government grant scheme, awarding grants to researchers holding PhDs and Habilitation degrees - the qualification that allows a $\mathrm{PhD}$ to teach at university on merit, as determined through a peerreview process. Second, there has been a movement away from the strict hierarchical structure which typified the traditional Polish laboratory. Instead of a team of researchers holding permanent positions and led by the head of the laboratory, contemporary Polish laboratories are associations of research groups consisting of principal investigators and graduate students working on the realization of research proposals.

Unfortunately, the government fellowships now offered in Poland to graduate students are inadequate to maintain a reasonable standard of living. As a result, principal investigators in Polish laboratories, facing strong competition from the West, will be unable to keep enough graduate students to perform research. Furthermore, there will be little incentive for the new generation of Polish scientists trained in western Europe to return to Poland and start their own laboratories, if they find a lack of qualified candidates for their research programmes.

What can be done to avoid this pessimistic scenario? Until economic conditions in eastern Europe improve, one solution would be to allocate a small percentage of the funds used in current EMBL and Max Planck fellowship programmes to a fellowship fund that would allow eastern European students to work in their home countries. Western European institutions funding fellowships could monitor the $\mathrm{PhD}$ programmes by sending advisers to participate in committee meetings, examinations and public defences of $\mathrm{PhD}$ theses.

Not only would this help to preserve and promote good-quality research and scientific training in eastern European countries, but it would also create a platform for collaboration between researchers in western and eastern Europe. Jaroslaw Marszalek, Krzysztof Liberek, Igor Konieczny

Department of Molecular and Cellular Biology, Faculty of Biotechnology, University of Gdansk, 24 Kladki, Gdansk 80822PL, Poland

\section{Arabidopsis could shed light on human genome}

Sir - Although only recently published in Nature $^{1}$, the entire sequence of the model plant Arabidopsis thaliana has been in the public domain for a considerable length of time. We note, however, that the papers analysing the data of the human genome substantially lack comparisons to the Arabidopsis genome.

Unlike any of the animal genomes sequenced to date, the Arabidopsis genome is virtually without significant gaps, and even includes a substantial amount of heterochromatic sequence which has been of great use in examining centromere structure and function ${ }^{2}$.

To cite but a single comparison arising from our own work, we have identified the entire complement of SNAREs in Arabidopsis ${ }^{3}$. Most notably, this mere slip of a plant encodes for more SNAREs (53, ref. 3) than humans do (35, ref. 4), including some classes of SNAREs which are not found in either human or yeast cells ${ }^{3}$.

We can understand that there is limited space for such analyses, but surely one should not omit significant information pertaining to an entire kingdom of eukaryotes!

If a comparison with yeast genes is of relevance to the evolution and function of the human orthologues, would not a comparison with a more distantly related and multicellular eukaryote reveal even more?

Anton A. Sanderfoot, Natasha V. Raikhel Department of Energy Plant Research Laboratory,
Michigan State University, East Lansing, Michigan 48824, USA

1. The Arabidopsis Genome Initiative Nature 408, 796-815 (2000). 2. Copenhaver, G. P. et al. Cell 100, 367-376 (2000). 3. Sanderfoot, A. A. et al. Plant Physiol. 124, 1558-1569 (2000). 4. Bock, J. B., Matern, H. T., Peden, A. A. \& Scheller, R. H. Nature 409, 839-841 (2001).

\section{Climate panel looked at all the evidence}

Sir - I read with interest your News article (Nature 409, 445; 2001) covering the approval of the Third Assessment Report of the Intergovernmental Panel on Climate Change (IPCC) Working Group I in Shanghai in January. As a coordinating lead author of one of the chapters, lead author of the technical summary and a member of the drafting team of the summary for policy-makers, I would like to clarify two points.

First, although climate modelling has advanced during the past five years, this is not the main reason for the revised range of temperature projections. The higher estimates of maximum warming by the year 2100 stem from a more realistic view of sulphate aerosol emissions. The new scenarios assume emissions will be reduced substantially in the coming decades, as this becomes technically and economically feasible, to avoid acid rain. Sulphate emissions have a cooling effect, so reducing them leads to higher estimates of warming.

Second, it is incorrect to say that the report does not consider new research on a possible change, or even shut-off, of the North Atlantic thermohaline circulation. This important new insight is addressed and assessed in detail in chapters seven and nine, amplified in the technical summary of Working Group I and explicitly carried over to the summary for policy-makers. All relevant and recent publications are cited. Thomas Stocker

Physics Institute, University of Bern, Sidlerstrasse 5, 3012 Bern, Switzerland

\section{Right person, wrong sex}

Sir-Although the enthusiasm of research institutions to showcase the important contributions from women scientists is understandable, I hope it hasn't extended so far as to change the gender of Clair Patterson, the man who gave us the age of the Earth - but was referred to in a book review (Nature 409, 20; 2001) as "she". William H. Casey

Department of Land, Air and Water Resources, University of California-Davis, 1 Shields Avenue, Davis, California 95616, USA

Nature replies - Apologies: the mistake was ours. 